\title{
The Impact of eLearning as a Knowledge Management Tool in Organizational Performance
}

\author{
Abdulla Alsharhan ${ }^{1}$, Said Salloum ${ }^{2,3, *}$, Khaled Shaalan ${ }^{1}$ \\ ${ }^{1}$ Faculty of Engineering \& IT, The British University in Dubai, 345015, UAE \\ ${ }^{2}$ School of Science, Engineering, and Environment, University of Salford, M16ORY, UK
}

${ }^{3}$ Research Institute of Sciences \& Engineering, University of Sharjah, 27272, UAE

\begin{tabular}{l} 
A R T I C L E I N F O \\
\hline Article history: \\
Received: 22 December, 2020 \\
Accepted: 04 February, 2021 \\
Online: 12 February, 2021 \\
\hline Keywords: \\
eLearning \\
Knowledge Management \\
SQL Databases \\
Organizational Performance \\
Organizational Learning \\
Technology Enhanced Learning \\
Computer Assisted Learning \\
\hline
\end{tabular}

\section{Introduction}

The fast-paced growth of information communication and technology is changing the world we live in into a knowledgebased society [1-3]. Within the context of the fourth industrial revolution and the knowledge-based economy, knowledge and learning systems play an important role in countries' competitiveness and organizational performance $(\mathrm{OP})$.

Knowledge capturing has become a strategic priority for many countries as an essential asset [4-8], especially if they want to remain competitive, driven by rapid development in knowledge creation and high demand for skilled human capital [9-12]. In the past, countries and organizations could achieve that by traditional educational and vocational training systems; however, the new era requires faster and shorter innovation cycles to remain innovative, which increases the need for continuous skilled and trained human capital with constant knowledge updates and skillsets.

The current workforce is transforming the traditional "singleskilled personnel to multi-skilled employees" who can manage multi-tasks under one job title. Such a goal will be possible only through new disruptive learning models and life-long learning

${ }^{*}$ Corresponding Author: Said Salloum, University of Sharjah, UAE. Tel:

+971507679647 Email: ssalloum@sharjah.ac.ae

Www.astesj.com

https://dx.doi.org/10.25046/aj0601102
(LLL) [13]. One of the knowledge-capturing and sharing tools is eLearning, where organizations and educational institutes can conduct training via electronic media via the internet. The COVID19 pandemic has forced many institutes and organizations to carry out their training and education activities via eLearning tools $[14,15]$. These activities revealed some limitations in current eLearning practices such as quality of interaction, lack of natural discussions, and limited nonverbal communication [16]. The reason can be anything, ranging from the use of old-fashioned eLearning practices to poor content and connection quality.

Alternatively, the use of technology-enhanced learning (TEL) via mobile is changing the learning process for many. Language learning apps, for example, are impacting how learning is taking place. A recent study concluded that Duolingo is fostering vocabulary and grammar development [17]. Other fun and engaging examples include fitness training apps from Adidas and Nike and musical instrument training apps like Yousician. TEL is becoming one of the trending topics in computer science as it utilizes the use of computers, mobile, software and apps to assist learning [6].

The advantage of TEL is that it guarantees learning continuity in different circumstances such as during pandemics, natural 
disasters, extreme weather conditions or for learners with disabilities. It frees the instructor from creating redundant lessons and devotes more time to developing quality learning materials. It also allows learners to engage in active and independent playbased learning and life-long learning [18].

Organizations need to encourage LLL via on-the-job training and eLearning methods. These learning methods will ensure that the current workforce is well equipped with the latest skills. Before knowledge is transformed into learning materials (eLearning), it is necessary to manage such knowledge first. Learning is an essential part of the Knowledge Management's (KM) life cycle, which complements the process of establishing, distributing, implementing, and managing the knowledge and information of an organization. It refers to a multidisciplinary approach to achieve organizational objectives by making the best use of knowledge. The most recent studies uncover the massive significance of presenting $\mathrm{KM}$ insights into eLearning frameworks. $\mathrm{KM}$ is believed to encourage an eLearning framework, where the joint effort between eLearning and KM will provide the single objective of hierarchical learning [19].

In this paper, we have included papers that are relevant to the role of KM, eLearning, and OP. We have reported a systematic review of the advances in eLearning in KM in response to OP. The objective is to provide overviews of the research studies within this field, how these concepts interact with each other, the main obstacles, and the recent emerging trends. More specifically, we have asked the following questions:

Table 1: Research question.

\begin{tabular}{|l|l|}
\hline$\#$ & Research question \\
\hline RQ1 & How is eLearning capabilities in KM impacting OP? \\
\hline RQ2 & $\begin{array}{l}\text { What are the challenges in implementing eLearning in } \\
\text { organizations? }\end{array}$ \\
\hline RQ3 & $\begin{array}{l}\text { What are some of the emerging trends and technologies in } \\
\text { eLearning? }\end{array}$ \\
\hline
\end{tabular}

\section{Literature Review}

This section will highlight the recent contribution that focuses on the subject of this study, including the discussion of the latest practices related to $\mathrm{KM}$, eLearning, training technologies, organizational learning, and performance.

\subsection{Origin of $K M$}

KM started within the management consulting community. They had realized how the internal networks in their organization is a vital tool to share and access information with their units, especially when these units were scattered in different geographical locations. While these consulting groups were working on facilitating their network to their use, they have gained some knowledge and recognized some good practices, such as developing and building these tools, expertise locators, lessonlearned databases, and designing dashboards.

They have realized the newly acquired expertise can be packaged, marketed, and sold to other similar entities, who might have multiple locations and experienced the same challenges. However, the new product needed a name. It seemed the term
"Knowledge Management" had appeared in this context for the first time in 1987. The KM term was spotted in an internal study in McKinsey on how to handle and utilize their information.

In 1993, the knowledge management went public at a conference organized by Ernst and Young. A young man at Ernst and Young came up with one of the first classic one-line definitions of KM. Tom Davenport defined KM as the process of capturing, distributing, and effectively using knowledge [20].

In 1998, the authors of [21] worked on a revised definition. They described $\mathrm{KM}$ as the activities related to utilizing and developing organization knowledge assets in line with organizational objectives. Early work by [22] in 2005 was among the first to link KM with innovation, as he defined $\mathrm{KM}$ as the purposeful and systemic coordination of an organization's individuals, technology, process, and structure to create values via reuse and innovation [23].

There were many models aroused around coordination between people, process, technology, and organization structure, including Wigg Model (1993), Zack Model (1996), Bukowitz and William Model (2000), and McElroy Model (2003). The following table explains the KM lifecycle steps, according to the four proposed models [24].

Table 2: KM lifecycle steps according to the four proposed models.

\begin{tabular}{|l|l|c|l|}
\hline WIGG & \multicolumn{1}{|c|}{ Zack } & $\begin{array}{c}\text { Bukowitz \& } \\
\text { Williams } \\
\mathbf{2 0 0 0}\end{array}$ & $\begin{array}{l}\text { McEIroy } \\
\mathbf{2 0 0 3}\end{array}$ \\
\hline Creation & Acquisition & Get & Learning \\
\hline Sourcing & Refinement & Use & Validation \\
\hline Compilation & Store & Learn & Acquisition \\
\hline Transformation & Distribution & Contribute & Integration \\
\hline
\end{tabular}

In [24], the author summarizes the steps in seven steps: Identity, Create, Store, Share, Use and Learn. For this review, the focus has been on the learning aspect and knowledge sharing with more details.

\section{2. $K M$ \& learning}

A study by [25] explained how KM and learning work together. The knowledge assets used and shared in the past could be the foundation for creating new and improving current ones. In situations where experts provide a certain understanding in a context, the employees gain and learn a new experience and apply that knowledge to their workplace. If the knowledge resources have been found insufficient or incomplete, the researcher goes back to the identity/creation phase where additional resources are created based on the gaps found. This repeatable process creates double-loop learning. Some of the activities that assist the learning stage are benchmarking, best practices, lessons learned, and knowledge gap analysis. Technological applications and examples can be found in learning management and help desk systems [24].

\subsection{KM in organizations}

In addition to organizations' ability to learn and unlearn, collective knowledge is an essential asset in improving OP. It would also increase profitability, which will eventually create and maintain a competitive advantage. A study by [26] defines 
organizational learning (OL) as using a purposeful learning process on individual, group, and system levels while changing the organization to satisfy its stakeholders. Scholars of [27] describe organizational learning as a social process where individuals engage in practices and speeches that reproduce the OL and expand it simultaneously.

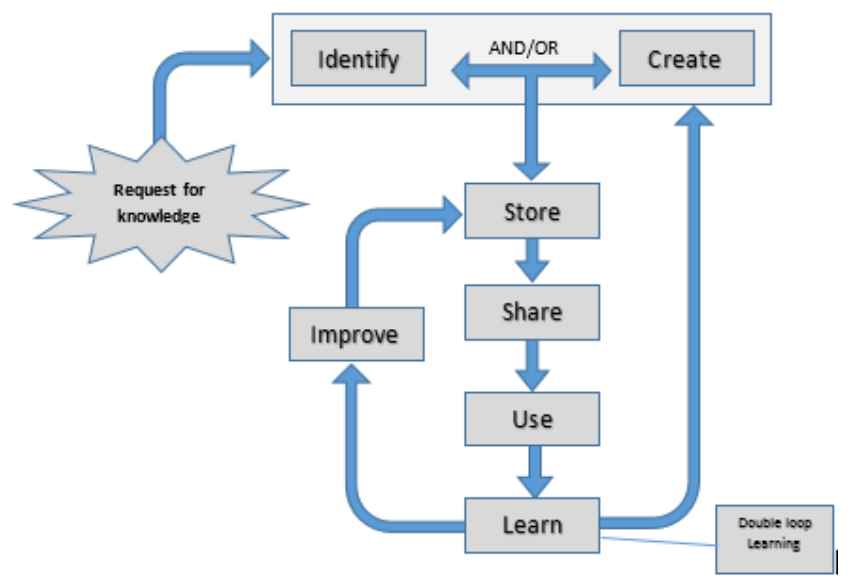

Figure 1: The KM Cycle (KMC) Model [24]

Four major vital areas were identified in [12]. These areas are the business drivers for the increased importance of $\mathrm{KM}$ in the organization today.

1. Globalization of business: The organization today is more global, multisite, multilingual, and multicultural.

2. Leaner organizations: Productivity is increasing faster, but it also needs to be done smarter as workers in KM are adapting to an increasing work pace and load.

3. Organization amnesia: Workforces are becoming mobile, which creates a challenge in sustaining knowledge in the organization and requires continuous learning. Employees are no longer expected to spend their entire lives in the same organization.

4. Technology advancement: People are connected seamlessly. The connections are not only ubiquitous but have radically changed expectations. Workers are expected to be "on" all the time, and response turnarounds are now measured by minutes, not weeks or even days [24].

One of the key challenges organizations face is the uncertainty of how exactly learning and KM impact OP. A dilemma that might create an ambiguity among leaders is how to optimize resources from KM. KM has no choice but to demonstrate how exactly they add value to the stakeholder [28]. A study by [29] examined the impact of KM on organizational learning, using OL in a mediating role. Results taken from 150 random samples show a close relationship between $\mathrm{KM}$ and OP. A critical insight is that $\mathrm{OL}$ is playing a mediating role between OP and KM. The study also revealed a positive relationship between emotional intelligence and OP.

In contrast, [30] investigated the effects of KM strategy and the effects of OL on OP. This study was conducted using a 5-point Likert-scale questionnaire on all levels of management in oil cooperation. The data collected from 161 managers confirmed that $\mathrm{KM}$ strategy is one of the preconditions and impactful factors regarding OP and innovation. In contrast, OL does not seem to have correlated with organizational innovation.

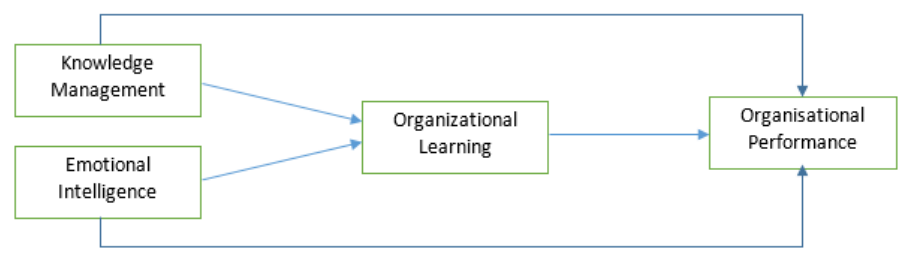

Figure 2: Relation between KM and OP [29].

\section{4. eLearning}

If we want to take a closer look at learning and training in the organization today, technology will be found as the driving force in workplace training. ATD's state of the industry report (2018) indicated that eLearning accounted for 40 percent of the formal learning hours used in 2017 [31]. The commonly known eLearning definition usually describes the activities of conducting learning using information and communication technologies. The authors of [32] identified that the most important remarkable milestones in learning are the evolution from distance learning to electronic learning to mobile learning. These three stages are in line with the impact of the Industrial Revolution in the eighteenth and nineteenth centuries and the Electronic Revolution in the last decade of the twentieth century [32].

Recent studies suggest that Massive Online Open Courses (MOOCs) will play a prominent role in organizational learning, provided these courses are relevant to the workplace and integrated effectively into the current training systems [33]. For many leaders and human resources trainers, eLearning is an easy way to provide workplace gamification content. The challenge remains that most training courses are theoretical and based on college courses, and they might not meet the corporate training version yet (except Udemy). However, a few work particularly with corporations to tailor-make their business knowledge into user-friendly courses, similar to ones we can identify with MOOCs platforms.

\subsection{Computer-Assisted Learning}

Computer-Assisted Learning (CAL) is one of the top 5 emerging trends in computer science in recent years [18]. This term can also be referring to Computer-Based Instruction (CBI), Computer-Aided Learning (CAL), or Computer-Aided Instruction (CAI) [34]. CAL can be defined as "learning that supplements regular classroom activities with computer activities during or surrounding classroom time" [35]. Apps are one well-known form of CAL applications. The authors of [36] found that educational apps can have added values to the learning process not available in the conventional eLearning tool, including repetitions, swift feedback, fun, creative tools, variety of methods, and pronunciation.

For this review, we can simply define CAL as "the learning procedures and environments facilitated through computers" [34]. The application of CAL is unlimited. One example of CAL applications can be seen in the medical field, which has recently become "a truth universally acknowledged" as a proven way to enhance the student learning process. In contrast, some instructors and trainers may lack the basic computer science skills needed to 
fully utilize technology in learning. Lacking key ICT skills might be one of the obstacles that limit the use of TEL tools [36].

\subsection{Technology-Enhanced Learning}

The emerging term Technology-Enhanced Learning (TEL) is a broad category that does not have a particular definition. It can refer to any type of technology that enhances the learning experience [37]. "Mentimeter" is an example of an interactive presentation platform that utilizes the capabilities of TEL. The trainer can build an interactive presentation; collect polls, data, and opinions from learners; and export the insights, data, and trends from participants' input. Media Technology and Interaction Design have identified many research areas around TEL, including learning analytics, the interplay of learning design and technology, design-based research, computer-supported collaborative learning, blended learning, sustainable design, and visualization for TELrelated issues [38]. A study by [39] provided an interesting application in eLearning. The Georgia Institute of Technology in the United States provided some of their online courses using virtual teaching assistants (TAs). The chatbot was developed using IBM Watson; the TAs can reply to student questions without informing the learner that they are artificial intelligence agents.

\section{7. eLearning in Information Technology (IT) Companies}

When it comes to technology companies and IT organizations, one can assume they are already ahead of others when it comes to their eLearning capabilities. There is little known about how they transform knowledge internally. One of the interesting findings that high-tech companies like Microsoft, Google, IBM, Cisco, Canon and Microsystems are using gamification capabilities to motivate and train their people. Canon technicians are learning how to fix and repair by literally dragging and dropping parts virtually, while Cisco has a platform called MyPlanNet, where employees play the role of a company's manager. Additionally, IBM developed a game simulation that allows employees to run an entire city [40].

Another common practice among technology companies is to share their online training materials externally. In other words, they focus on training individuals before they hire them, particularly because high-tech companies require highly skilled human resources already trained in their preferred way of working. For example, IBM- and Google-certified specializations can be found on eLearning platforms like Coursera, Microsoft courses, Edx and Udacity. This practice not only cuts training costs for IT organizations but may also become an additional profit centre as they license these certificates. In addition, companies can access a pool of talented full-stack programmers when needed.

\subsection{Life-long Learning and eLearning}

Life-long learning (LLL) sometimes gets confused with adult learning. LLL is a process where individuals seek learning opportunities to develop their knowledge, skills and life (Richardson, 1978 in Mouzakitis \& Tuncay, 2011). Individuals who have an interest in LLL have a continuous ambition to learn and are responsible for their self-learning. According to the European Commission (briefing paper 20, 2001), LLL has become a targeted objective for learning policies at the national and international levels in recent years. In [41], the author conducted empirical research on 138 employees and found that seven out of ten employees prefer eLearning course delivery over classroom attendance. These data support how eLearning should play a vital role in executing lifelong training, especially for employees between 55 and 64 years old in all sectors.

\section{Methodology}

In an attempt to follow a preferred reporting items for systematic reviews and meta-analyses (PRISMA), research should provide an explicit statement and form questions including participants, interventions, comparisons, outcomes, and study design (PICOS) [42]. Therefore, the research questions (Table 1) have been formed based on PICOS principles. The following detailed systematic review is based on results from research papers obtained in different online journals and databases that focus on eLearning, KM, and OP, in addition to CAL.

\subsection{Data sources and Search Strategies}

Different articles were found to match the searching criteria. In particular, 211 materials were found in credible online journals. All the results were found using WorldCat.org, Google Scholar and Crossref databases, as shown in Figure 3. The searching algorithms used included the presence of the required elements in the research objective; additionally, the exclusion aided to sort out the sources which were undesirable, and no organizational context was side-lined, leaving only the required data. The following keywords have been used to locate information from the journal kw: ("computer-assisted education" OR "computer-assisted learning" OR "computer-assisted training" AND "knowledge management" AND "computer science") AND kw: ("e-learning" OR "eLearning" OR "online learning") AND (yr: 2016-2020). Additional keywords used to refine the search are "eLearning" AND "organizational performance" OR "organizational performance". Table 3 gives more insights on the inclusion and exclusion criteria.

Table 3: Inclusion and exclusion criteria

\begin{tabular}{|l|l|}
\hline \multicolumn{1}{|c|}{ Inclusion } & \multicolumn{1}{c|}{ Exclusion } \\
\hline Articles published in 2016 or later & Articles published before 2016 \\
\hline $\begin{array}{l}\text { Should be related to KM } \\
\text { methodologies, processes, or lifecycles }\end{array}$ & $\begin{array}{l}\text { Related to KM or OP } \\
\text { but not linked to eLearning }\end{array}$ \\
\hline $\begin{array}{l}\text { Should be related to computer-assisted } \\
\text { learning or techniques }\end{array}$ & $\begin{array}{l}\text { Related to eLearning but not linked } \\
\text { to KM or OP }\end{array}$ \\
\hline Should have five or more citations & Has fewer than five citations \\
\hline Papers are in English & Papers are not in English \\
\hline Articles & Books or book chapters \\
\hline
\end{tabular}

\subsection{Challenges faced}

There is no one clear definition of the field of computerassisted learning, making it challenging to locate all the research about it and its relation to the eLearning and KM cycle. Some related terms are computer-assisted education, computer-assisted instruction and TEL. The category of TEL may be too broad or have no direct relation with eLearning and OP yet. 


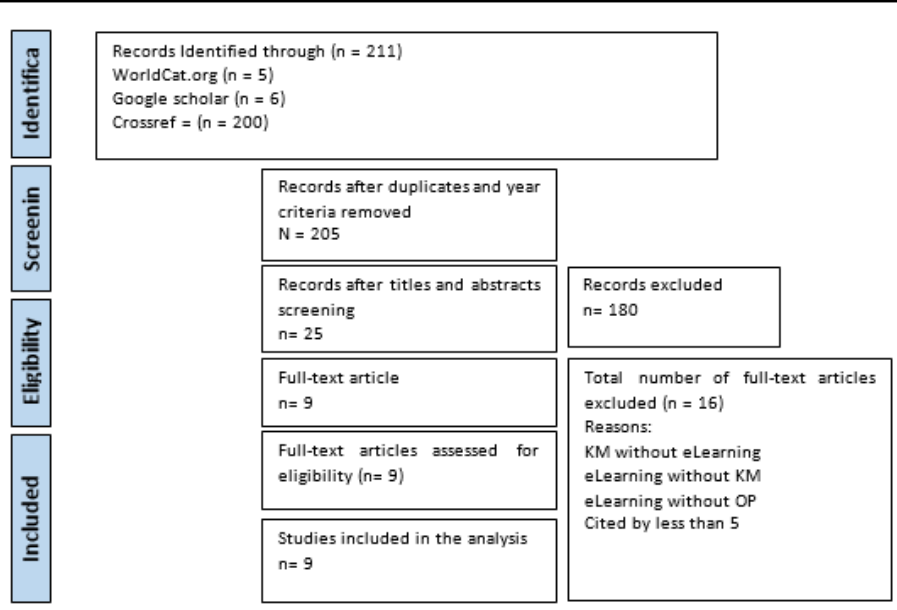

Figure 3: Research PRISMA model [43]

\section{Results}

The following is the result of reviewing the shortlisted nine research articles published between 2016 and 2020 on the impact of KM strategy and learning capabilities on OP.

\subsection{RQ1. How are eLearning capabilities in KM impacting OP?}

Previous studies mentioned that organizational eLearning capabilities in their KM context could enhance OP in many ways. Table 4 summarizes the main findings of the analysed KM researches in the context of eLearning and OL.

The finding revealed the many ways eLearning capabilities can impact OP. eLearning is a scalable tool that can increase individuals' competency levels on large scales. Every single individual can contribute to their organizational competitiveness, accelerate innovation rate and ultimately achieve a knowledgebased economy for their societies [19]. eLearning can also cut training and travel costs and ensure consistent training for all, increasing the quality and ensuring everyone is getting the same high-quality training [44]. Using the right eLearning capabilities can make a difference in the impact of the performance and quality result. eLearning Management Systems such as Moodle have proven to be the most effective tool in knowledge transferring compared to other distance learning tools such as email and teleconferences. Picking the right eLearning tool is essential because it increases the knowledge sharing among individuals and eventually increases performance and productivity [45]. Developing and sharing eLearning content on open platforms can also lead to gaining customer trust, attracting talent and enhancing organizational reputation. eLearning can also work as a new revenue stream for organization setting on knowledge assets [33].

Table 4: Analysis of KM research with regards to eLearning and OL.

\begin{tabular}{|c|c|c|c|c|}
\hline Ref. & Purpose & $\frac{\overline{0}}{\frac{0}{6}}$ & Finding & $\stackrel{\varrho}{\Xi}$ \\
\hline [19] & $\begin{array}{l}\mathrm{KM} \text { and eLearning in } \\
\text { Organisations. }\end{array}$ & 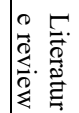 & $\begin{array}{l}\text { eLearning will not run } \\
\text { alone without the KM. }\end{array}$ & 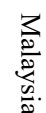 \\
\hline
\end{tabular}

\begin{tabular}{|c|c|c|c|c|}
\hline [33] & $\begin{array}{l}\text { The role of open } \\
\text { educational resources } \\
\text { (OER) in the eLearning } \\
\text { movement }\end{array}$ & 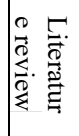 & $\begin{array}{l}\text { Opportunities and } \\
\text { advantages and limitation } \\
\text { of OERs }\end{array}$ & $\overrightarrow{\vec{\partial}}$ \\
\hline [44] & $\begin{array}{l}\text { E-Training \& } \\
\text { employees' } \\
\text { performance. }\end{array}$ & $\underset{\Xi}{\stackrel{2}{2}}$ & $\begin{array}{l}\text { Significant relationship } \\
\text { between e-training } \\
\text { (including e-training } \\
\text { infrastructure \& } \\
\text { methods) and job } \\
\text { performance, }\end{array}$ & 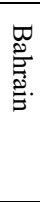 \\
\hline [45] & $\begin{array}{l}\text { The effectiveness of } \\
\text { eLearning on change } \\
\text { management and KM } \\
\text { strategy in the } \\
\text { organization using } \\
\text { "Moodle". }\end{array}$ & 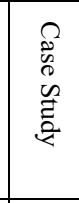 & $\begin{array}{l}\text { eLearning is the most } \\
\text { effective method of } \\
\text { knowledge transfer. }\end{array}$ & 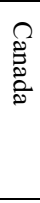 \\
\hline [46] & $\begin{array}{l}\text { Study deep learning } \\
\text { applications for } \\
\text { developing resource for } \\
\text { eLearning platform. }\end{array}$ & 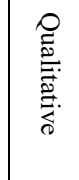 & $\begin{array}{l}\text { Deep learning enables } \\
\text { the reusing repurposing } \\
\text { current eLearning } \\
\text { resources to create more } \\
\text { personalized experience. }\end{array}$ & 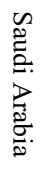 \\
\hline [47] & $\begin{array}{l}\text { How mobile learning } \\
\text { experiences can } \\
\text { support the } \\
\text { co-creation of new } \\
\text { knowledge. }\end{array}$ & 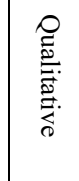 & $\begin{array}{l}\text { That mobile technology } \\
\text { is an excellent way to } \\
\text { stimulate the } \\
\text { social co-creation of new } \\
\text { knowledge. }\end{array}$ & 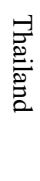 \\
\hline [48] & $\begin{array}{l}\text { A review of the current } \\
\text { literature on digitally } \\
\text { based serious games \& } \\
\text { gamification using } \\
\text { digital tools in } \\
\text { corporate training. }\end{array}$ & 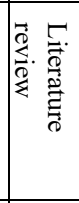 & $\begin{array}{l}\text { Design principles for a } \\
\text { game-based training } \\
\text { methodology. }\end{array}$ & 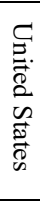 \\
\hline [49] & $\begin{array}{l}\text { The role of OL in } \\
\text { employee engagement. } \\
\text { The role of eLearning } \\
\text { resources quality in } \\
\text { bank sector. }\end{array}$ & $\underset{\Xi}{\stackrel{2}{2}}$ & $\begin{array}{l}\text { OL positively impacts } \\
\text { employee } \\
\text { engagement, and } \\
\text { eLearning resources } \\
\text { quality partially impact } \\
\text { employee engagement. }\end{array}$ & $\overline{\mathrm{Z}}$ \\
\hline [50] & $\begin{array}{l}\text { To integrate inquiry } \\
\text { learning and KM into a } \\
\text { flipped classroom to } \\
\text { programming students } \\
\text { in a higher education } \\
\text { setting. }\end{array}$ & 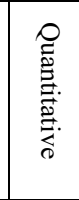 & $\begin{array}{l}\text { Integrating KM and } \\
\text { inquiry-based approach } \\
\text { into a flipped classroom } \\
\text { can improve students' } \\
\text { performance. }\end{array}$ & 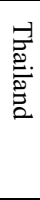 \\
\hline
\end{tabular}

\subsection{RQ2. What are some obstacles to organisation learning} using eLearning?

There are many factors that could undermine eLearning's effectiveness in any organisation. The first factor is the human factor. Some employees will resist sharing or allowing knowledge to transform because it might threaten their existence and will make them replaceable. Another factor related to human nature is the willingness to learn. Employees being in their comfort zones too long will not benefit from eLearning materials, and they might need some explanation on how eLearning can be useful for their career advancement [19]. Another human-related factor is the widespread belief that free and accessible content is worthless. The language [33] and the user interface can also be an obstacle to accessing the eLearning platform. The platform needs to be easy and straightforward to use, or the employee should be trained on it if necessary [44]. The quality source of the eLearning is also vital to ensure that useful and accurate messages are being delivered. This factor is particularly critical in some industries, such as the financial sector [49]. 
Content high initial development cost can also be a challenging factor in some small and medium organisations. However, the long-term impact can be scalable and widely accessible [46]. Intellectual properties of the content itself can also be restricted in some cases and limit the opportunity of sharing it, and this can go both ways [33]. Finally, the top management endorsement is vital to ensure that a knowledge-sharing and learning culture is in place $[19,44]$.

\subsection{RQ3. What are some of the emerging trends and technologies in eLearning?}

Many significant trends emerged in eLearning in the last decade (Table 5). Some of them impact learners' outcomes and enhance their learning experience. These trends include Mobile Computer-Supported Collaborative Learning (mCSCL) [47], game-based learning - Gamification [48], flipped classroom [50], using Deep learning and artificial Inelegance in the eLearning field [46] and Open Educational Resources (OER) [36]. What the majority of these trends have in common can be summarized in their ability to provide social interaction, fun, and interactive and unlimited access. The instructor becomes a facilitator; learners are in control, and they co-create the new knowledge [47].

Table 5: The main trends and technologies eLearning found in the reviewed papers

\begin{tabular}{|c|c|c|c|c|c|c|c|c|c|}
\hline 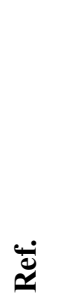 & & 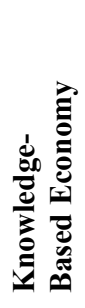 & 泀 & $\begin{array}{l}\frac{0}{\bar{E}} \\
\bar{\Sigma}\end{array}$ & & 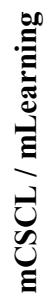 & 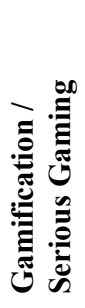 & 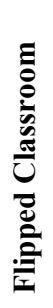 & 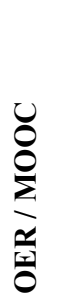 \\
\hline [19] & $X$ & X & & & & & & & \\
\hline [33] & $X$ & & & & & & & & \\
\hline [44] & & & $X$ & & & & & & \\
\hline [45] & X & & & $X$ & & & & & \\
\hline [46] & $X$ & & & & $X$ & & & & \\
\hline [47] & & & & & & X & & & \\
\hline [48] & & & $X$ & & & & $X$ & & \\
\hline [51] & X & & & & & & & $X$ & \\
\hline$[50]$ & $\mathrm{X}$ & & & & & & & & $\mathrm{X}$ \\
\hline
\end{tabular}

\section{Discussion}

\section{1. eLearning capabilities \& $O P$}

In [19], the study discussed the impact from an economic development perspective. As the economic evolution is witnessing a shift from an industrial-based economy to a knowledge-based economy, the whole country's performance, and not just the organization's, depends on the human capital being equipped with the necessary academic skills. Learning capabilities remained the key challenge in a country like Malaysia to fully transform its economy into a knowledge-based one. This study valued learning capability as a vital role for remaining competitive. Successful organizations are those that can capture intalactual assets by managing their knowledge. The paper also acknowledged the critical role of top management, as they need to understand the best way to combine and share the knowledge sources to improve the company's performance. Once learning capabilities are rooted and embraced as part of the organizational culture; it will lead to increasing the competency level of every single individual, driven by the role of its KM system. Only then can the organization reach its full potential and increase its competitiveness performance [19]. However, the author did not specify what methodology was used to reach his findings, and he did not support his findings with examples or case studies.

The study by [33] pointed out how eLearning capabilities could reduce training costs and have a long-term impact on reducing operational expenses, which would lead eventually to better financial performance. Some researchers think organizations that create and share open-learning resources should be exempt from taxes.

The results of [44] also confirmed the [33] finding in cost savings. The study highlighted the importance of eLearning and its impact on individual performance. One direct impact of endorsing eLearning capability can be a huge amount of saving in training. This saving includes travel expense and training time. Other advantages include flexibility in self-based training and the variety and availability of training content. The eLearning model can also guarantee unified training for all, which will keep the resource inside the organization. The business will not be interrupted by those who take leave for training. This will increase the workers' productivity and the number of skilled and trained human capital, which ultimately will allow the business to remain competitive [44]. In addition, long-term organizational success is linked to embracing a learning culture among employees. One significant finding is the role of the eLearning infrastructure on employee performance.

The results of [45] are in line with the above findings, as the authors also found that eLearning is the most effective method of knowledge transfer. The authors examined how different learning capabilities can impact executing a successful KM strategy and improve the chance of knowledge sharing among individuals, which ultimately will lead to improving an individual's productivity and OP.

Three knowledge transfer types were used (email, teleconference, and eLearning), and eLearning proved to have the most significant impact. It created a sharing culture and a common place to retrieve information, but the authors also pointed out that further investigation was needed to ensure that the reuse of this module would lead to performance improvement [45]. Although the study used Moodle, an open-source eLearning platform, it did not discuss the security issues associated with open systems and platforms. 
The study also highlighted the importance of matching learning modules with the right organizational needs; this will result in improving OP. In addition, the learning capabilities involving the use of eLearning modules can constitute a useful tool for sharing knowledge. This system will allow "just in time" training that will enable employees to cope with the necessary changes to their overall performance.

Another way in which an organization can use eLearning to stimulate their performance involves sharing their knowledge in an open platform or on the company's website, where they can attempt to gain customers' trust and attract talent's confidence. It is also a way to enhance the organizational image and reputation. In addition, the distribution of free learning materials can lead to an individual doing something for free in return. A study [33] has also highlighted the increased willingness of individuals to engage in an activity associated with a company after benefitting from free services such as knowledge sharing.

The results of [46] support the proposal of [33]. Deep learning applications in eLearning can automate this process and boost the repurposing of current organizational learning resources to create more customized experiences and content using the power of the natural language process (NLP) and machine learning.

\subsection{Challenges in eLearning}

In [19], the authors pointed out that, as everyone could imagine, eLearning practices were not a comfortable ride. The biggest obstacle in this paper was not the technology or the KM itself. Surprisingly, it lay in the human factor of the process. It has been found that employees can resist sharing the necessary knowledge. Individuals in organizations may argue that sharing the knowledge they have will threaten their existence in the organization, leading to their replacement with younger, cheaper staff. In addition, the embracing of comfort zone culture in organizations can be a barrier to making use of the full potential of eLearning tools. However, this finding could have been enhanced if it is supported by more concrete evidence. Further studies are needed to support this claim.

In [33], the study referred to an unfortunate widespread belief that if something like eLearning is free and accessible by all, such as OER, it might mean it is worthless. However, these concerns are not in line with those of [52], who found OER improves students' grades and addresses attainment gap concerns. They also offer opportunities for part-time students and populations historically underserved by higher education.

Intellectual properties were also raised in this study, where content producers restricting the reuse, editing, combining, or distributing of training materials. Language can also be a barrier for those who do not speak English as a second language. The same also applies to cultural diversity; the contextual gap can be another challenge that will result in a barrier for understanding not only the words but the context of the concept expressed through them.

The results of [44] are consistent with that, as the findings pointed out the importance of the simplicity and the accessibility of the
eLearning platform as it might be an obstacle of the user interface was not interactive or attractive enough [44].

In [53] the authors have discussed the role of the eLearning resource quality and how the message of the content can be lost in the process. The issue related to updating multiple organizations, scattered in different locations from one credible source. Banks industries, for example, are impacted by several changes based on the economic situation. This industry is regulated by government economic policies that keep constantly changing to respond to the economic situation. Delivering these new updates effectively and swiftly is essential to bank employees. Banks are usually developing eLearning capabilities to inform their employees with these continuous updates; however, lacking a suitable mechanism to understand the quality of the learning resources can affect the understanding of these updates, resulting in outdated products and services, and eventually effects the bank's performance [53]. Unfortunately, high-quality content is usually associated with high cost. The results of [46] reinforce that by flagging out the cost involved in developing learning content. Although eLearning facilitates learning anytime and anywhere, the initial cost of developing eLearning resources can be a barrier to further deployment on an organizational level [46]. However, [46] also suggests tackling the cost linked with content development by using deep learning applications in reusing and purposing existing content, and save cost for the long-run.

\section{3. eLearning emerging trends}

In [47], the paper has discussed the mobile devices as one of the learning tools enhancing corporative learning. They describe the mobile learning operationally by a cooperative social process, supported by handsets, where the participant uses their handsets to interact internally and externally, to share and generate new knowledge. They used the terminology "mobile computersupported collaborative learning" (mCSCL) to describe these activities. The paper also found six emerging perspectives on what learners are experiencing in mobile learning nowadays. They summarised their finding in the following points: 1) Social interaction is necessary, 2) Unlimited learning experience, 3) Learning becomes fun and interactive, 4) Instructor is becoming facilitator, 5) Learners control their learning between each other, 6) Learners value the co-creation of new knowledge [47].

A study by [48] highlighted another emerging field in adapting eLearning in an organization using game-based learning. These learning tools utilize the psychological readiness of individuals to engage in games. Game-based learning uses the same motivational and addiction mechanism used in video games and applies it to real-world activities to make them more enjoyable and attractive. The efforts focused on employing gamification techniques in the workplace to motivate, training and recruiting. Game-based training increases engagement, motivation, performance, and retention.

The study uses some empirical evidence as a successful application of game-based learning in the workplace environment. 
Including L'Oreal, IBM, Cisco, Deloitte, and McDonald's. Whereby these companies have developed and implemented gamification and serious games as part of their overall training strategy. The impact has been measured by reducing lost time, an increase in engagement, and an increase in revenue up to USD 30 million [48].

In [50], the results suggested a flipped-classroom approach to improve learning outcomes. Flipped classroom or flipped workshop is considered an effective learning way by many researchers. The flipped classroom concept focuses on post-course activity, forcing learning to prepare and preview the material outside the class hours. For example, online learning tools are usually utilized, and learners have to attend online learning materials provided by the trainer before joining the actual class. The early finding indicates an improvement in learner's performance.

Authors of [46] have highlighted deep learning using artificial intelligence as one of the emerging trends in many eLearning fields. The value of deep learning comes in its ability to offer learners intuitive algorithms, automated delivery of content, the ability to swiftly reuse the current resource, and decrease the cost of content development. Some deep learning applications in eLearning includes Personalized learning path, Chatbots Performance indicator and Virtual teaching assistant.

The study of [33] discussed the role of OER in eLearning applications. The advantages of OER have gained increased attention worldwide; this could be for OER's potential in overcoming educational, demographic, economic, and geographic limitations. OER can come with various models, for example, the 4A model characterizes OER in the following As Accessible, appropriate, accredited, and affordable. In contrast, the 4R model characterized it in a 4R model, these Rs are: Reuse (open license of applying all or part for an individual goal), Revise (Editing, translating and modifying the content, Remix (Combining two materials to create a new resource and Redistribute (sharing with others).

The MOOC is one of the well-known concepts that has emerged from OERs. MIT's open courseware, for example, is the largest provider of such courseware. Up to 2015, MIT has successfully archived 2,250 training courses, and 450 training courses are being added annually. Many educational institutes have followed MIT's practices policy in publishing free open courses on MOOC platforms, such as Coursera, Edx, and Udacity platforms. Some corporations have even started to follow that practice, including IBM, Microsoft, and Google [33].

\section{Conclusions}

This paper has explained the importance of eLearning as a knowledge transfer tool on OP. It has also discussed the challenges and obstacles of applying eLearning tools and has highlighted the recent eLearning trends from 2016 to 2020. This study has further shown how individual LLL is critical in creating a knowledge- based economy and how eLearning capabilities provide an ideal solution for that mission. The research has shown that eLearning can impact OP in many ways. Also shown was the importance of matching learning modules with the right organizational needs in order to achieve the desired performance. One of the more significant findings is that sharing knowledge externally on an open eLearning platform can lead to gaining customers, attracting talent, and increasing a company's reputation and value. However, many of the findings discussed need further investigation. There is little known on how eLearning capabilities have impacted organizations during and after COVID-19 in different regions. Further study suggested studying the impact of eLearning as an LLL practice. Moreover, researchers must look at how students, young people, and senior employees engage in the eLearning platform, determine what motivates them, and decide how to validate their learning outcomes.

\section{Acknowledgement}

This is part of a project that was conducted at the British University in Dubai.

\section{References}

[1] S.A. Salloum, K. Shaalan, "Adoption of e-book for university students," in International Conference on Advanced Intelligent Systems and Informatics, Springer: 481-494, 2018.

[2] S.A. Salloum, C. Mhamdi, B. Al Kurdi, K. Shaalan, "Factors affecting the Adoption and Meaningful Use of Social Media: A Structural Equation Modeling Approach," International Journal of Information Technology and Language Studies, 2(3), 96-109, 2018.

[3] S.A. Salloum, M. Al-Emran, S. Abdallah, K. Shaalan, "Analyzing the Arab Gulf Newspapers Using Text Mining Techniques," in International Conference on Advanced Intelligent Systems and Informatics, Springer: 396-405, 2017, doi:10.1007/978-3-319-64861-3_37.

[4] S.A. Salloum, M. Al-Emran, K. Shaalan, "The Impact of Knowledge Sharing on Information Systems: A Review," in 13th International Conference, KMO 2018, Slovakia, 2018.

[5] S.K. Al Mansoori S., Salloum S.A., "The Impact of Artificial Intelligence and Information Technologies on the Efficiency of Knowledge Management at Modern Organizations: A Systematic Review.,' In: Al-Emran M., Shaalan K., Hassanien A. (Eds) Recent Advances in Intelligent Systems and Smart Applications. Studies in Systems, Decision and Control, Vol 295. Springer, Cham, 2021.

[6] A. Almansoori, M. AlShamsi, S.A. Salloum, K. Shaalan, Critical Review of Knowledge Management in Healthcare, 99-119, 2021, doi:10.1007/978-3030-47411-9 6 .

[7] S.K. Areed S., Salloum S.A., "The Role of Knowledge Management Processes for Enhancing and Supporting Innovative Organizations: A Systematic Review.," In: Al-Emran M., Shaalan K., Hassanien A. (Eds) Recent Advances in Intelligent Systems and Smart Applications. Studies in Systems, Decision and Control, 295, Springer, Cham, 2021.

[8] A.A.A. Mehrez, M. Alshurideh, B.A. Kurdi, S.A. Salloum, Internal Factors Affect Knowledge Management and Firm Performance: A Systematic Review, 2021, doi:10.1007/978-3-030-58669-0 57.

[9] S.K. Habeh O., Thekrallah F., Salloum S.A., "Knowledge Sharing Challenges and Solutions Within Software Development Team: A Systematic Review.," In: Al-Emran M., Shaalan K., Hassanien A. (Eds) Recent Advances in Intelligent Systems and Smart Applications. Studies in Systems, Decision and Control, 295, Springer, Cham, 2021.

[10] A.Y. Zainal, H. Yousuf, S.A. Salloum, "Dimensions of Agility Capabilities Organizational Competitiveness in Sustaining," in Joint European-US Workshop on Applications of Invariance in Computer Vision, Springer: 762-772, 2020

[11] S.A. Salloum, M. Alshurideh, A. Elnagar, K. Shaalan, "Mining in Educational Data: Review and Future Directions," in Joint European-US Workshop on Applications of Invariance in Computer Vision, Springer: 92$102,2020$. 
[12] S.A. Salloum, W. Maqableh, C. Mhamdi, B. Al Kurdi, K. Shaalan, "Studying the Social Media Adoption by university students in the United Arab Emirates," International Journal of Information Technology and Language Studies, 2(3), 83-95, 2018.

[13] M. Raman, S. Gopinathan, "Role of knowledge and learning systems in fostering work-life balance," Knowledge Management \& E-Learning: An International Journal, 8(2), 213-215, 2016.

[14] A.S. Alnaser, M. Habes, M. Alghizzawi, S. Ali, "The Relation among Marketing ads, via Digital Media and mitigate (COVID-19) pandemic in Jordan The Relationship between Social Media and Academic Performance: Facebook Perspective View project Healthcare challenges during COVID19 pandemic View project," Dspace.Urbe.University, (July), 2020.

[15] R.S. Al-Maroof, S.A. Salloum, A.E. Hassanien, K. Shaalan, "Fear from COVID-19 and technology adoption: the impact of Google Meet during Coronavirus pandemic,” Interactive Learning Environments, 1-16, 2020.

[16] J.P. Lahti, T. Shinasharkey, "Corporate eLearning Position in Finnish Energy Business-Power Market Perspective."

[17] K.R. Finardi, R.G. Leao, G.B. Amorim, "Mobile assisted language learning: Affordances and limitations of Duolingo," Education and Linguistics Research, 2(2), 48-65, 2016.

[18] M. Frot, 5 Trends in Computer Science Research | Top Universities, Top Universities, 2019.

[19] A.S.M. Zahari, S.M. Salleh, R.M.R. Baniamin, "Knowledge Management and e-Learning in Organisations," in Journal of Physics: Conference Series, IOP Publishing: 22051, 2020.

[20] M.E.D. Koenig, "What is KM? Knowledge management explained," KM World, 4, 2012.

[21] T.H. Davenport, L. Prusak, Working knowledge: How organizations manage what they know, Harvard Business Press, 1998.

[22] K. Dalkir, "The knowledge management cycle," Knowledge Management in Theory and Practice. Oxford: Elsevier, 25-46, 2005.

[23] D. Hislop, R. Bosua, R. Helms, Knowledge management in organizations: A critical introduction, Oxford university press, 2018.

[24] M. Evans, K. Dalkir, C. Bidian, "A holistic view of the knowledge life cycle: the knowledge management cycle (KMC) model," The Electronic Journal of Knowledge Management, 12(1), 47, 2015.

[25] M.M. Evans, N. Ali, "Bridging knowledge management life cycle theory and practice," in International Conference on Intellectual Capital, Knowledge Management and Organisational Learning ICICKM 2013-Conference Proceedings, 156-165, 2013.

[26] M.D. Nancy, The Organizational Learning Cycle: How We Can Learn Collectively - Nancy M. Dixon - Google Books, 2000.

[27] I. V Popova-Nowak, M. Cseh, "The meaning of organizational learning: A meta-paradigm perspective," Human Resource Development Review, 14(3), 299-331, 2015.

[28] D. Wilkinson, "The 3 key issues for learning and knowledge management Research.," in The OR Briefing - - Oxcogntia LLC., 2017.

[29] H. Mubeen, H. Ashraf, Q.A. Nisar, "Impact of emotional intelligence and knowledge management on organizational performance: Mediating role of organizational learning," Journal of Management Info, 11(2), 35-52, 2016.

[30] M.S. Nikabadi, S. Bagheri, S.A. Mohammadi-Hoseini, "Effects of knowledge management strategy and organizational learning capability on innovation-driven performance in an oil company," Knowledge Management \& E-Learning: An International Journal, 8(2), 334-355, 2016.

[31] ATD Research, 2018 State of the Industry, 2018.

[32] D. Keegan, "The Future of Learning: From eLearning to mLearning.," 2002.

[33] M. Mosharraf, F. Taghiyareh, "The role of open educational resources in the eLearning movement," Knowledge Management and E-Learning, 8(1), 1021, 2016, doi:10.34105/j.kmel.2016.08.002.

[34] M. Schittek, N. Mattheos, H.C. Lyon, R. Attström, "Computer assisted learning. A review," European Journal of Dental Education: Review Article, 5(3), 93-100, 2001.

[35] G. Hussain, I. Farooque, "Evaluation of the Effectiveness of Computer Assisted Learning to Improve the Clinical Examination Skills of First Year Medical Undergraduates," Original Research Article, 3(8), 391-96, 2016, doi:10.16965/ijims.2016.144.

[36] L. Kolâs, H. Nordseth, R. Munkvold, "Learning with educational apps: A qualitative study of the most popular free apps in Norway," in 2016 15th International Conference on Information Technology Based Higher Education and Training (ITHET), IEEE: 1-8, 2016.

[37] E. Cullen, What is Technology Enhanced Learning, and why is it important? - Mentimeter, Mentimeter, 2018.

[38] O. Bälter, Technology Enhanced Learning | KTH, Media Technology and Interaction Design, 2019.

[39] B.Y. Ekren, V. Kumar, "Next Generation Digital Engineering Education:

www.astesj.com
MOOCs," in 5th NA International Conference on Industrial Engineering and Operations Management, Michigan: 1-11, 2020.

[40] J. Witte, R. Westbrook, M.M. Witte, "Gamification and Training," Global Conference on Education and Research , 1, 56-58, 2017, doi:10.5038/25726374-v1.

[41] G. Mouzakitis, N. Tuncay, "E-Learning and lifelong learning," Turkish Online Journal of Distance Education, 12(1), 166-173, 2011.

[42] A. A. Mohammed, Raj Gururajan, A.H. Baig, "Primarily Investigating into the Relationship between Talent Management and Knowledge Management in Business Environment," Knowledge Management in Business Environment., 2-8, 2017, doi:10.1145/3106426.31094441.

[43] D. Moher, L. Shamseer, M. Clarke, D. Ghersi, A. Liberati, M. Petticrew, P. Shekelle, L.A. Stewart, "Preferred reporting items for systematic review and meta-analysis protocols (PRISMA-P) 2015 statement," Systematic Reviews, 4(1), 1, 2015, doi:10.1186/2046-4053-4-1.

[44] K.B. Kamal, M. Aghbari, M. Atteia, "E-training \& employees' performance a practical study on the ministry of education in the Kingdom of Bahrain," Journal of Resources Development and Management, 18, 2016.

[45] D. Tessier, K. Dalkir, "Implementing Moodle for e-learning for a successful knowledge management strategy," Knowledge Management \& E-Learning: An International Journal, 8(3), 414-429, 2016.

[46] A. Muniasamy, A. Alasiry, "Deep Learning: The Impact on Future eLearning.," International Journal of Emerging Technologies in Learning, 15(1), 2020.

[47] G. Lim, A. Shelley, D. Heo, "The regulation of learning and co-creation of new knowledge in mobile learning," Knowledge Management \& E-Learning: An International Journal, 11(4), 449-484, 2019.

[48] K. Larson, "The Corporate Playground: A Review on Game-Based Learning in Enterprise Training," in E-Learn: World Conference on E-Learning in Corporate, Government, Healthcare, and Higher Education, Association for the Advancement of Computing in Education (AACE): 737-748, 2019.

[49] I.Y.A. Durairaj, T. Thiruvenkadam, M. Subrahmanian, "THE ROLE OF ORGANIZATIONAL LEARNING IN EMPLOYEE ENGAGEMENT AND THE MEDIATING ROLE OF E-LEARNING RESOURCES QUALITY," The Online Journal of Distance Education and E-Learning, 6(4), 2018.

[50] K. Thongkoo, P. Panjaburee, K. Daungcharone, "Integrating inquiry learning and knowledge management into a flipped classroom to improve students' web programming performance in higher education," Knowledge Management and E-Learning, 11(3), 304-324, 2019, doi:10.34105/j.kmel.2019.11.016.

[51] T. Thiruvenkadam, M. Subrahmanian, "THE ROLE OF ORGANIZATIONAL LEARNING IN EMPLOYEE ENGAGEMENT AND THE MEDIATING ROLE OF E-LEARNING RESOURCES QUALITY," The Online Journal of Distance Education and E-Learning, 6(4), 78, 2018.

[52] N.B. Colvard, C.E. Watson, "The Impact of Open Educational Resources on Various Student Success Metrics The Impact of Open Educational Resources on Student Success Metrics," International Journal of Teaching and Learning in Higher Education, 30(2), 262-276, 2018.

[53] M. Durairaj, C. Vijitha, "Educational data mining for prediction of student performance using clustering algorithms," International Journal of Computer Science and Information Technologies, 5(4), 5987-5991, 2014. 